\title{
Design for safety: theoretical framework of the safety aspect of BIM system to determine the safety index
}

\author{
Ai Lin Evelyn Teo, George Ofori, Imelda Krisiani Tjandra and Hanjoon Kim \\ National University of Singapore, Singapore
}

\begin{abstract}
Despite the safety improvement drive that has been implemented in the construction industry in Singapore for many years, the industry continues to report the highest number of workplace fatalities, compared to other industries. The purpose of this paper is to discuss the theoretical framework of the safety aspect of a proposed BIM System to determine a Safety Index. An online questionnaire survey was conducted to ascertain the current workplace safety and health situation in the construction industry and explore how BIM can be used to improve safety performance in the industry. A safety hazard library was developed based on the main contributors to fatal accidents in the construction industry, determined from the formal records and existing literature, and a series of discussions with representatives from the Workplace Safety and Health Institute (WSH Institute) in Singapore. The results from the survey suggested that the majority of the firms have implemented the necessary policies, programmes and procedures on Workplace Safety and Health (WSH) practices. However, BIM is still not widely applied or explored beyond the mandatory requirement that building plans should be submitted to the authorities for approval in BIM format. This paper presents a discussion of the safety aspect of the Intelligent Productivity and Safety System (IPASS) developed in the study. IPASS is an intelligent system incorporating the buildable design concept, theory on the detection, prevention and control of hazards, and the Construction Safety Audit Scoring System (ConSASS). The system is based on the premise that safety should be considered at the design stage, and BIM can be an effective tool to facilitate the efforts to enhance safety performance. IPASS allows users to analyse and monitor key aspects of the safety performance of the project before the project starts and as the project progresses.
\end{abstract}

Keywords: BIM, design, IPASS, safety, Singapore.

Paper type: Research article

\section{Introduction}

Building Information Modelling (BIM) has been identified as the key technology to improve productivity in the Singapore construction industry (BCA, 2013). The Building and Construction Authority (BCA) has introduced a BIM Fund as part of the \$ $\$ 250$-million Construction Productivity and Capability Fund (CPCF) to assist construction companies to improve the levels of productivity in the industry (BCA, 2015).

BIM offers the potential for performance improvement in construction along many parameters. Among others, BIM can be used to improve safety performance (Benjaoran and Bhokha, 2010; Zhang, et al., 2013; Choi, Choi and Kim, 2014). In Singapore, where it is now a compulsory requirement for building plans to be submitted to the authorities for approval in BIM format, its

Copyright: Construction Economics and Building 2016. (C) 2016 Ai Lin Evelyn Teo, George Ofori, Imelda Krisiani Tjandra and Hanjoon Kim. This is an Open Access article distributed under the terms of the Creative Commons Attribution 4.0 Unported (CC BY 4.0) License (https://creativecommons.org/licenses/by/4.0/), allowing third parties to copy and redistribute the material in any medium or format and to remix, transform, and build upon the material for any purpose, even commercially, provided the original work is properly cited and states its license.

Citation: Teo, A.L.E., Ofori, G., Tjandra, I.K. and Kim, H. 2016. Design for safety: theoretical framework of the safety aspect of BIM system to determine the safety index. Construction Economics and Building, 16(4), 1-18. DOI: http://dx.doi.org/10.5130/AJCEB.v16i4.4873

Corresponding author: Imelda Krisiani Tjandra; Email - imelda.tjandra@gmail.com

Publisher: University of Technology Sydney (UTS) ePress 
potential should be maximized. With the long-term goal to achieve zero injury in the construction industry (WSH Council, 2010), BIM could also be utilised to help realise this objective.

The Singapore government has been actively promoting the use of BIM in the construction industry. Moreover, raising productivity in all sectors of the economy has been a top national priority. The government has introduced a number of safety initiatives, with the aim of reducing overall workplace fatalities to 1.8 per 100,000 workers by 2018. Despite the safety improvement drive that has been in place in the construction industry in Singapore for some decades, the industry continues to report the highest number of workplace fatalities, compared to other industries.

Taking advantage of the government's initiatives in raising productivity (of which encouragement of, and support for, BIM application is a key part) and reducing workplace fatalities, there are opportunities for construction companies and practitioners to maximise the potential of BIM to help improve productivity and safety in the industry. However to date no study has attempted to incorporate the two project parameters together, or which considered the relationship between the two performance parameters. Finally, although research has been conducted into the ability of BIM to help enhance productivity, the potential of BIM to improve both productivity and safety performance has not been fully explored. Hence, the research project aimed to develop an intelligent monitoring system which incorporated both the productivity and safety performance criteria using BIM for simultaneous exploration. The specific objectives were to:

- study the relationship between productivity and safety, and how the application of BIM can help to enhance the level of performance on these two project parameters;

- assess the current situation of the construction industry in Singapore, particularly pertaining to productivity and safety;

- ascertain the level of BIM implementation in the industry;

- study the potential of BIM to facilitate the attainment of productivity and safety improvement; and

- design a comprehensive monitoring system for improving productivity and safety through the application of BIM.

This paper reports on part of the larger research project which is presented in Figure 1. The paper focuses on how BIM could be used to improve safety performance (in the rest of the discussion in this paper, productivity is excluded, that means Section $4 \mathrm{c}$ and its associated parts in Sections 5, 6 and 7 in Figure 1 are excluded). The specific objectives of this paper are to:

- ascertain the current workplace safety and health (WSH) situation in the construction industry in Singapore;

- explore how BIM can be used to improve safety performance in the industry; and

- discuss the development of the safety aspect of the tool, Intelligent Productivity and Safety System (IPASS) which was created, and its validation exercise.

In the rest of this paper, the first section considers "Design for Safety with ConSASS Assessment"; it is followed by the "Potential of BIM for Improving Safety". The field study and the findings from it are next presented. The "Proposed Theoretical Framework of the Safety Aspect of IPASS" and its validation are then discussed before some concluding remarks are made. 


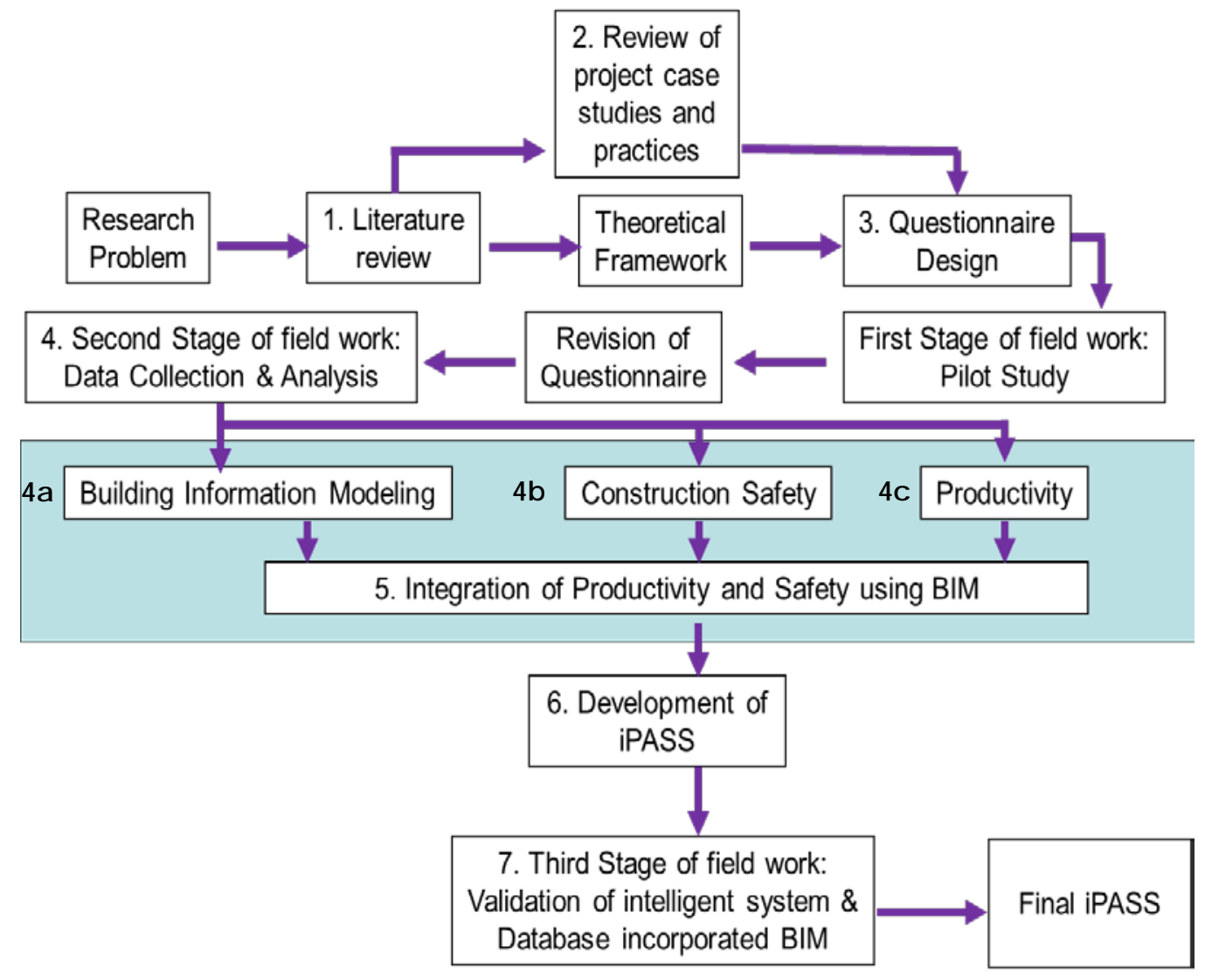

Figure 1: Stages of the entire research project

\section{Design for safety with ConSASS assessment}

DfS, which is also referred to as Designing for Construction Safety (DfCS) (Behm, 2005a), Prevention through Design (PtD) (Schulte, et al., 2008; Ku, 2014), safe design (Safe Work Australia, 2012) and Construction Hazards Prevention through Design (CHPtD) (Toole and Gambatese, 2008; Gangolells, et al. (2010), is the deliberate consideration of construction site safety in the design phase of a project (Behm, 2005a). The main notion is that, by addressing safety during the design process, hazards will be eliminated or reduced during construction (Behm, 2005a). The focus is also on reducing rework through effective project planning (WSH Council, 2015).

Traditionally, designers have not addressed construction worker safety in their design decisions (Gambatese, Hinze and Haas, 1997) particularly owing to the attitude that construction work is inherently unsafe and a project's design has no effect on safety (Gambatese, Hinze and Haas, 1997). Construction worker safety was often regarded as the sole responsibility of the contractor, although the safety performance on a project may be largely determined by decisions made by the designer (Hinze and Wiegand, 1992). The consideration of the safety aspects during design was traditionally limited to the end user of the completed facility rather than that of the construction workers (Hecker and Gambatese, 2003). Construction worker safety is often overlooked until the start of the construction phase (Gambatese, Hinze and Haas, 1997).

The concept of DfS started to gain attention in the 1990s, with Gambatese, Hinze and Haas (1997) applying the concept in the US construction industry. They incorporated an accumulation of best practices into a "Design for Construction Safety ToolBox" that assists designers in recognising project-specific hazards and implementing the design suggestions in a project's design. The toolbox links the design and construction phases to improve construction worker safety. Gangolells, et al. (2010) developed a quantitative methodology that allows designers to 
evaluate the safety-related performance of designs by comparing the overall safety risk level of various construction designs prior to the construction stage. Behm (2005b) and Gambatese, Behm and Rajendran (2008) confirm the link between design and construction safety. Toole and Gambatese (2008) have identified four specific trajectories that CHPtD is likely to follow in future: increased prefabrication, increased use of less hazardous materials and systems, increased application of construction engineering, and increased spatial investigation and consideration.

In the UK, the concept of DfS was first made a mandatory requirement by law through the Construction Design and Management (CDM) Regulations 1994, which came into force in 1995 (Zou and Sunindijo, 2015). In Australia, the Work Health and Safety (WHS) Act 2011 defined the responsibilities of designers with regards to the health and safety aspects of their designs (Zou and Sunindijo, 2015). In Singapore, the WSH Council launched the "Guidelines on Design for Safety in Buildings and Structures" in 2008. The guidelines seek to bring together stakeholders including client, designers and contractors to help reduce risks at source (WSH Council, 2011b). The DfS regulations took effect in August 2014, requiring safety features for workers to be incorporated into the design. The rules apply to projects with contract values of S\$10 million and above.

Safety in the construction industry in Singapore has always been a concern, and significant efforts have been made to address it. Considering the slow progress of safety improvement in the industry, in early 2015, the WSH Council, in consultation with the industry, launched a series of new action plans (WSH Council, 2015). The action plans focus on leadership, procurement, DfS training, WSH culture and WSH practices. Leadership and commitment by clients and contractors in setting up WSH policies, goals and expectations for all other project players is key in the effort to improve the safety performance of the construction industry. Clients, starting with those in the public sector, should consider past WSH performance as part of the criteria for the selection of contractors in tendering exercises for their projects. The WSH Council works together with developers, contractors and the professional institutions to develop training programmes to ensure that workers are competent to work safely. Clients and contractors work together to build a WSH culture in the industry. Sharing of good WSH practices among stakeholders in the industry will help to raise WSH standards. DfS will be strengthened by incorporating it into the curricula of the institutions of higher learning (IHLs) and ensuring that sufficient time and resources are provided for the design and execution of every project. ConSASS audits are now mandatory for all construction sites with a contract sum of $\mathrm{S} \$ 30$ million or more (WSH Council, 2015).

ConSASS is a tool to measure the maturity of the WSH system, aiming at providing a standardized scoring system for the construction industry. ConSASS was aimed at providing an easy cross comparison between worksites in terms of the effectiveness in managing safety and health risks at work on these sites. Hence, it was expected to motivate the contractors to strive for improvement in managing safety and health risks at their worksites. Evaluation of the maturity profile of each element of the Safety and Health Management System (SHMS) enables the management of the worksite to focus its attention on the weaker elements so as to improve the overall maturity of their SHMS. ConSASS also makes it possible for clients to assess the capabilities of each contractor in managing WSH risks before awarding the contracts. ConSASS forms part of the national WSH 2018 strategy, and is under the third strategy, "Promoting the Benefits of WSH and Integrating WSH into Business" (WSH Council, 2010). Under the strategy, clients are encouraged to factor in ConSASS results in their selection of contractors. The aim was to achieve the adoption of ConSASS at all construction sites by 2015, with 80 percent of sites achieving at least ConSASS Band III.

The questions in the ConSASS checklist are grouped into four bands which reflect the increasing level of maturity of the elements being audited. The bands are: 
- Band I: Whether the SHMS has a particular provision;

- Band II: Whether the content of the particular provision is sufficiently comprehensive;

- Band III: Whether the particular provision is well-implemented on site; and

- Band IV: Best practices

The audit checklist of ConSASS was derived from audit questionnaires from the Singapore Standards for Occupational Safety and Health Management System (SS506), Code of Practice for Safety Management Systems for Construction Worksites (CP 79) and the Universal Assessment Instrument (UAI) published by the American Industrial Hygiene Association (AIHA). The questions in the checklist are structured along Deming's Plan-Do-Check-Act (PDCA) cycle as follows: OSH Policy (Plan), Planning (Plan), Implementation and operation (Do), Checking and corrective action (Check) and Management review (Act) (WSHC, 2008)

\section{Potential of BIM for improving safety}

BIM is a three-dimensional modelling technology and an integrated process that allows the building professionals of various disciplines to share, discuss and explore the building project digitally before it is built. This allows the professionals, especially architects, engineers and contractors, to analyse and resolve potential design clashes before construction begins (BCA, 2011). This facilitates better teamwork among the professionals, helping to reduce unnecessary reworks after construction starts on site.

BIM offers a wide range of benefits at various stages of the construction process. BIM has the potential to improve the overall safety performance of the construction project due to the possibility of eliminating potential risks and uncertainty (Smith, 2007). From the safety perspective, BIM offers a number of benefits which include raising the safety awareness of the team (Benjaoran and Bhokha, 2010) and identifying the likely conflicts and risks that would have arisen due to the changes in work practices (Gu and London, 2010). The ability of BIM to enable the detection of possible problems during construction through visualization allows the application of BIM to be in accordance with the principle of DfS, which aims to consider safety at the earliest opportunity. In the UK, Winfield (2015) argues that the data-rich environment of BIM can assist companies to implement the CDM Regulations 2015, where everyone involved in a construction project has responsibility for health and safety. The potential of BIM to assist project participants in the fulfillment of their CDM duties lies in its ability to carry out simulations to identify the safest construction arrangements or processes, and establish the possible construction hazards. In addition BIM databases could be used to track important health and safety information relating to changes in design, materials, equipment and personnel. In the event of an accident, the data in the model could be used in investigations, reducing the time and costs of such investigations and any disputes that may arise.

According to Zhang et al. (2015a), safety performance in construction is often poor due to the lack of a pro-active or formalized approach to construction safety planning. Zhang et al. (2015a) noted that the link between planning for safety and work-task execution is weak because many contractors use two-dimensional drawings in applying hazard-prevention techniques. This may largely impede the realization of worker safety, health and productivity on a construction project. There is a need for an approach to obtain the geometric parameters of the proposed constructed item, visualise the workspace and detect workspace conflicts, and this is enabled by BIM and its environment (Zhang et al., 2015a).

The potential of BIM in improving safety in the construction industry has been explored by a number of researchers who developed automated safety checking platforms which are able to detect, and thus help to prevent, work-at-height hazards (Benjaoran and Bhokha, 2010; Zhang, et al., 2013). These systems are able to automatically analyse a building model and suggest necessary 
preventive safety measures before construction starts. Choi et al. (2014) developed a BIM-based evacuation system for high-rise and complex buildings. Their system allows architects, designers and owners to evaluate the proposed design at the initial planning stage to ensure that the design meets the safety requirements. Wetzel and Thabet (2015) developed a BIM-based framework for safety in facility management using rules algorithm to output safety information. A group of researchers have used rule algorithm to develop construction safety ontology that enabled more effective inquiry on safety knowledge based on rules for job hazard analysis. They found that the links between construction safety management and information models are missing (Zhang et al., 2014; Zhang et al., 2015b; Malekitabar et al., 2016; Zou et al., 2016). Numerous research works have explored the use of BIM to enhance safety performance (see Table 1) but none of these studies has attempted to apply the integration of BIM, DfS, ConSASS, Control Measure and Hazards Identification to enhance safety performance on construction sites.

Despite the potential of BIM for improving safety and the current push from the Singapore government to encourage and facilitate the utilization of BIM in construction projects, most local firms still use BIM purely for simple tasks such as submission of building plans to the authority for approval, and visualization. Some firms, however, have embarked on relatively advanced levels of BIM for more sophisticated tasks such as clash detection, simulation, estimation, preparation of structural details, and environmental analysis (Teo et al, 2015). Construction firms do acknowledge the benefits of BIM, such as its ability to facilitate communication and coordination, and enable visualization and clash detection. However, in general, (Teo et al, 2015) found that the construction firms in Singapore are not taking full advantage of BIM.

\section{Field study}

A systematic investigative process (see Figure 1) was carried out to increase current knowledge on BIM and safety by discovering new facts in this study. It comprises two general categories: (1) Basic research inquiry aimed at increasing scientific knowledge; and (2) Applied research effort aimed at using basic research findings for solving problems by developing a new BIM-based system. The process used to collect information and data for the purpose of developing the IPASS system includes a literature review, interviews, a questionnaire-based survey, and BIMsystem-analysis review. Another key aspect of the study was an analysis of both present and historical official statistics/information on safety.

In the field study, in order to obtain good basic information on the situation in the construction industry in Singapore with respect to the issues being investigated, only senior personnel were approached for interviews. They were CEOs, Directors, BIM Managers and Safety Managers who have been involved in the local authorities Safety and/or BIM initiatives. Moreover, on the online questionnaire-based survey, there was a covering letter in which it was indicated that only senior personnel with a certain period of relevant working experience could participate in the survey (Section A of the online questionnaire contained a question requesting respondents to indicate the number of years they had worked in the construction industry). The methods employed in this study are deemed to be appropriate to the subject of the research. IPASS is based on a study which ascertained the current situation in the industry from interviews and a survey. It uses BIM technology to integrate the concepts as well as aspects of application of buildable design, prevention and control of hazards, and safety assessment.

The on-line questionnaire survey, from which the information for the part of the field study reported in this paper was obtained, sought to ascertain how senior personnel in Singapore's construction industry perceived: the current practice of safety and BIM in the industry, the level of awareness of BIM and the potential of BIM in improving safety of the industry. In most of the questions in the survey instrument, the respondents were requested to indicate the extent to 
which they agreed with various statements, on a five-point Likert scale. For example, when respondents were asked to rate the extent to which they agreed with each of the statements on the potential of BIM, they were required to select a number from 1 to 5 , where 1 represented "strongly agree" and 5 stood for "strongly disagree". In addition, for the firms' WSH practices, there were two possible responses, which were "Yes" and "No". The respondents were requested to respond to the questions in the survey from the perspective of their firms.

Table 1: Previous research on the application of BIM to enhance safety performance

\begin{tabular}{|c|c|c|c|}
\hline Phase & Focus Areas & Outline & Author (year) \\
\hline Design & Design for Safety & $\begin{array}{l}\text { Tool for design suggestions that alert designer } \\
\text { when project-specific safety hazard is identified }\end{array}$ & $\begin{array}{l}\text { Gambatese et al. } \\
\text { (1997) }\end{array}$ \\
\hline Design & Design for Safety & $\begin{array}{l}\text { Tool to estimate time, cost and worker safety } \\
\text { impacts of specific design and construction } \\
\text { process alternatives for projects }\end{array}$ & Slaughter (2003) \\
\hline Design & $\begin{array}{l}\text { BIM design / rules } \\
\text { algorithm }\end{array}$ & $\begin{array}{l}\text { Algorithms that automatically analyze a building } \\
\text { model to detect hazards and suggest preventive } \\
\text { measures to users are developed for different } \\
\text { cases involving fall-related hazards }\end{array}$ & Zhang et al. (2013) \\
\hline $\begin{array}{l}\text { Design and } \\
\text { Construction }\end{array}$ & $\begin{array}{l}\text { Virtual reality / BIM } \\
\text { 4D }\end{array}$ & $\begin{array}{l}\text { Explores relationships between construction } \\
\text { safety and digital design practices }\end{array}$ & Zhou et al. (2012) \\
\hline Construction & Virtual reality & $\begin{array}{l}\text { Database and virtual reality application to allow } \\
\text { for a walkthrough to identify hazards and select } \\
\text { accident prevention approaches }\end{array}$ & $\begin{array}{l}\text { Hadikusumo and } \\
\text { Rowlinson (2002) }\end{array}$ \\
\hline Construction & $\begin{array}{l}\text { BIM 4D (Fall } \\
\text { Hazards only) }\end{array}$ & Site organisation to promote safety against falls & $\begin{array}{l}\text { Sulankivi et al. } \\
(2009)\end{array}$ \\
\hline Construction & $\begin{array}{l}\text { BIM } 4 \mathrm{D} / \text { rules } \\
\text { algorithm }\end{array}$ & $\begin{array}{l}\text { Conceptual model that enables forecasting of } \\
\text { safety risks for different trades }\end{array}$ & $\begin{array}{l}\text { Rozenfeld et al. } \\
(2009)\end{array}$ \\
\hline Construction & $\begin{array}{l}\text { BIM 4D / rules } \\
\text { algorithm (Fall } \\
\text { Hazards only) }\end{array}$ & $\begin{array}{l}\text { Rules-based system that analyzes design } \\
\text { information to detect working-at-height hazards }\end{array}$ & $\begin{array}{l}\text { Benjaoran and } \\
\text { Bhokha (2010) }\end{array}$ \\
\hline Construction & $\begin{array}{l}\text { BIM 4D / rules } \\
\text { algorithm (Falls \& } \\
\text { Hazardous } \\
\text { environments only) }\end{array}$ & $\begin{array}{l}\text { Use of real-time location system for worker } \\
\text { tracking to provide warnings when one is } \\
\text { approaching hazardous areas }\end{array}$ & $\begin{array}{l}\text { Hammad et al. } \\
\text { (2012) }\end{array}$ \\
\hline Construction & $\begin{array}{l}\text { BIM 4D / rules } \\
\text { algorithm (Falls } \\
\text { hazards only) }\end{array}$ & $\begin{array}{l}\text { Automated safety checking in a 4D simulation } \\
\text { application }\end{array}$ & $\begin{array}{l}\text { Sulankivi et al. } \\
\text { (2013) }\end{array}$ \\
\hline Construction & Rules algorithm & $\begin{array}{l}\text { Identification of accidents, risks and hazards } \\
\text { influencing safety of construction workers }\end{array}$ & Melzner et al. (2013) \\
\hline Construction & $\begin{array}{l}\text { BIM design / BIM } \\
4 \mathrm{D} \text { (Fall hazards } \\
\text { only) }\end{array}$ & $\begin{array}{l}\text { BIM-based approach for communicating and } \\
\text { implementing construction safety plan }\end{array}$ & $\begin{array}{l}\text { Azhar and Behringer } \\
\text { (2013) }\end{array}$ \\
\hline Construction & Rules algorithm & $\begin{array}{l}\text { Construction site safety knowledge using rules } \\
\text { algorithm }\end{array}$ & Zhang et al (2014) \\
\hline Construction & $\begin{array}{l}\text { Ontology-based } \\
\text { modelling (job } \\
\text { hazard analysis) }\end{array}$ & $\begin{array}{l}\text { Development of ontology-based semantic } \\
\text { modelling of construction knowledge towards } \\
\text { automated safety planning for job hazard } \\
\text { analysis }\end{array}$ & Zhang et al (2015a) \\
\hline Construction & Fall hazard & $\begin{array}{l}\text { BIM-based fall hazard identification ONLY and } \\
\text { prevention in construction planning }\end{array}$ & Zhang et al (2015b) \\
\hline Construction & Risk management & $\begin{array}{l}\text { Review of risk management through BIM and } \\
\text { BIM-related technologies }\end{array}$ & Zou et al (2016) \\
\hline Construction & Rules checking & $\begin{array}{l}\text { Suggestion of five sets of safety risk drivers that } \\
\text { can influence either the probability or standards }\end{array}$ & $\begin{array}{l}\text { Malekitabar et al } \\
\text { (2016) }\end{array}$ \\
\hline $\begin{array}{l}\text { Operation } \\
\text { and } \\
\text { Maintenance }\end{array}$ & Facility management & $\begin{array}{l}\text { Use of BIM-based framework to support safety } \\
\text { facility management }\end{array}$ & $\begin{array}{l}\text { Wetzel and Thabet } \\
\text { (2015) }\end{array}$ \\
\hline
\end{tabular}


The target respondents included senior personnel of main contractors and consultants. The main contractors were identified from the BCA Directory of Registered Contractors and Licensed Builders (BCA, 2014a). A total of 383 main contractors were selected. The consultants included architects, structural engineers, mechanical and electrical (M\&E) engineers, and quantity surveyors. They were identified from the lists of members of the respective professional institutions in Singapore, consisting of the Singapore Institute of Architects (SIA), Association of Consulting Engineers Singapore (ACES) and Singapore Institute of Surveyors and Valuers (SISV). Using this method, a total of 454 consultants were selected. Hence, the total number of target respondents was 837. Each of the 837 target respondents was sent an e-mail message containing a link to the questionnaire survey in August 2014. 55 e-mail messages bounced back due to the use of the wrong e-mail addresses, 59 usable responses were received, which reflected a response rate of 7.54 per cent (Table 2).

Table 2: Response rate

\begin{tabular}{|c|c|c|c|c|c|c|}
\hline Respondents & Population & $\begin{array}{l}\text { E-mail } \\
\text { invitations } \\
\text { sent out }\end{array}$ & $\begin{array}{l}\text { Wrong e-mail } \\
\text { addresses }\end{array}$ & $\begin{array}{l}\text { Correct e-mail } \\
\text { addresses }\end{array}$ & $\begin{array}{l}\text { Usable } \\
\text { responses }\end{array}$ & $\begin{array}{l}\text { Response } \\
\text { rate }\end{array}$ \\
\hline $\begin{array}{l}\text { Main } \\
\text { contractors }\end{array}$ & 2,709 & 383 & 22 & 361 & 25 & $6.93 \%$ \\
\hline $\begin{array}{l}\text { Architectural } \\
\text { firms }\end{array}$ & 377 & 323 & 15 & 308 & 15 & $4.87 \%$ \\
\hline $\begin{array}{l}\text { Structural and } \\
\text { M\&E } \\
\text { engineering } \\
\text { firms }\end{array}$ & 142 & 87 & 13 & 74 & 17 & $22.97 \%$ \\
\hline $\begin{array}{l}\text { Quantity } \\
\text { surveying firms }\end{array}$ & 623 & 44 & 5 & 39 & 2 & $5.13 \%$ \\
\hline Total & 3,851 & 837 & 55 & 782 & 59 & $7.54 \%$ \\
\hline
\end{tabular}

The 59 firms consisted of 25 main contractors, 15 architectural firms, 17 structural and M\&E engineering firms, and 2 quantity surveying firms. The respondents who completed the questionnaires for their firms comprised: (i) persons in the upper management level (33.90 per cent); (ii) middle management level personnel (32.20 per cent); and (iii) professionals (33.90 per cent). The respondents were asked to answer the questions from the perspective of their firms' policies and practices.

\section{Findings}

A key research objective was to investigate the WSH practices of the construction industry. Moreover, from the review of the literature (WSHC, 2010; WSHC, 2015; Teo et al., 2015) it was found that good WSH practices will lead to good safety performance on site. Thus, the respondents were asked questions on the firms' corporate practices with regard to safety.

In answer to a number of "Yes" or "No" questions on the firms' corporate practices with regard to safety, many of the respondents from the 25 main contractors reported that their firms have implemented the necessary policies, programmes and procedures on WSH practices. All the respondents reported that their firms: (i) have policies for the improvement of safety on the firms' projects (\#1 of Figure 2); (ii) conduct a periodic review of the firms' safety policy, vision, mission and/or objectives (\#2 of Figure 2); (iii) assess the overall WSH performance on the firm's projects (\#7 of Figure 2); and (iv) have targets of WSH performance levels to achieve on the firm's projects (\#10 of Figure 2). On the remaining questions, only one to three firms did not have such practices. Five main contractors do not have WSH incentive programs. 

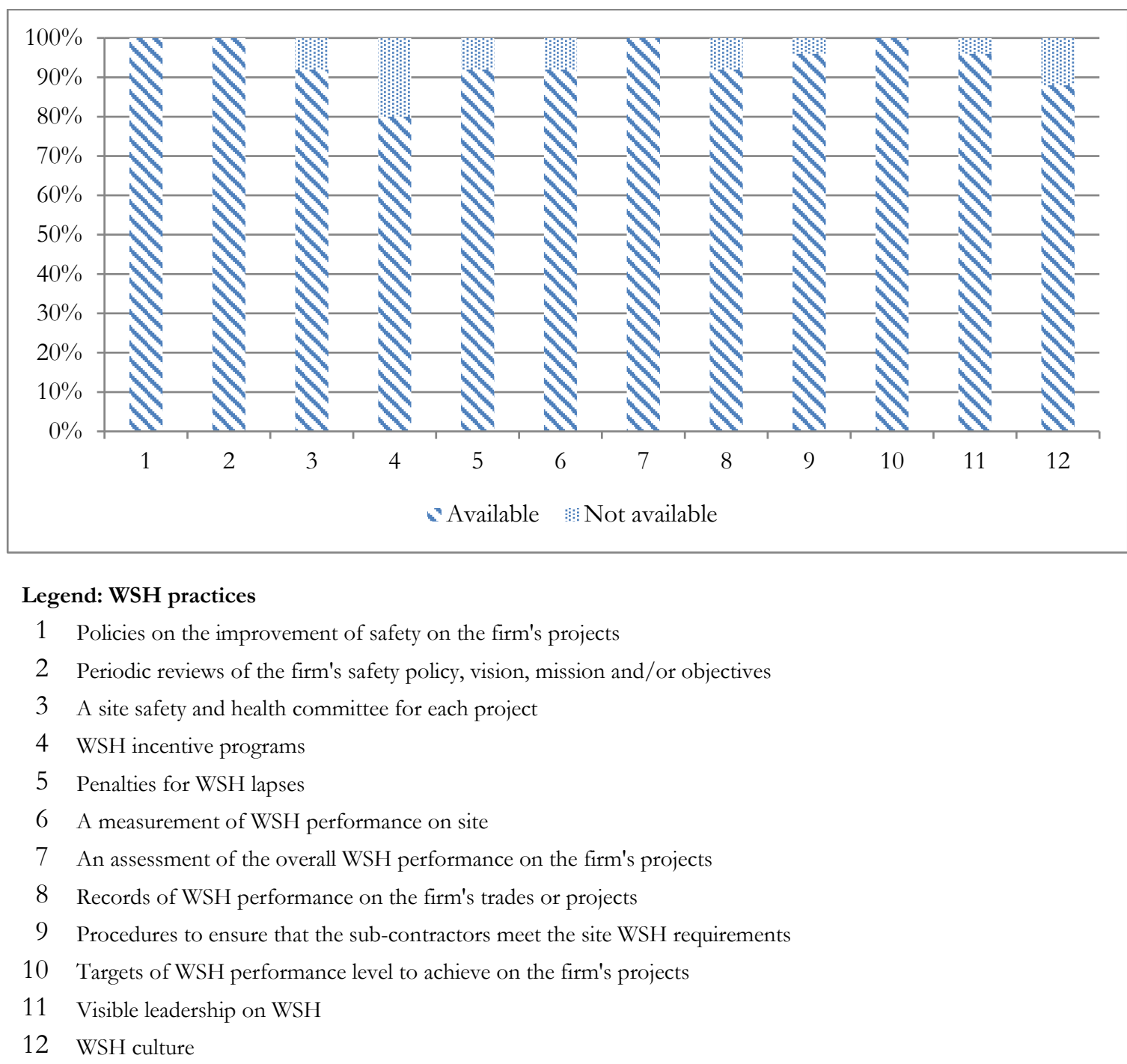

Figure 2: WSH practices (implementation by Contractors at Construction Stage)

To ascertain the respondents' views on the potential of BIM, they were asked to indicate their agreement with various possibilities on a scale of 1-5 (1 being "strongly agree" and 5 being "strongly disagree"). The respondents agreed with all the potentials listed, with the two items that were ranked the lowest being pre-project planning and clash detection. The three items that were ranked the highest were: safety monitoring using actual construction data; hazard identification; and safety simulation (Table 3).

From the field study, it can be concluded that the government's drive to ensure that construction firms in Singapore put in place the necessary WSH policies, programs and procedures has been successful. However, the official statistics showed that the construction industry has the highest fatality rate among the sectors of the economy (WSHI, 2015b). It can be concluded therefore that having the necessary WSH policies, programs and procedures in place are not sufficient to improve safety performance. The findings of this study are in line with the results of similar previous studies (Zhang et al., 2014; Zhang et al., 2015a; Malekitabar et al., 2016; Zou et al., 2016), highlighting the need for a technological advance to improve safety performance in construction projects. Capitalizing on the promotion of BIM and DfS in the industry, an intelligent system using BIM was developed. The system, which is discussed in the next section, focuses on the improvement of safety performance in the industry using the principles of DfS 
and ConSASS assessment. The system was developed to be able to perform seven potential applications of BIM as indicated in Table 3.

This section explores the safety aspect of the proposed system using the BIM platform (Figure 3). The aim of the system, in relation to safety, is to determine a safety index for a building using BIM technology and DfS via ConSASS. It focuses on the prevention and control of hazards detected in the structural and wall systems of the building; and incorporation of ConSASS assessment.

The system was designed to be able to proactively identify and mitigate risks. Risk mitigation through an embedded control system follows the hierarchy of hazard control, such as elimination, substitution, engineering control, administrative control and Personal Protective Equipment (PPE), prescribed by WSH Council (2011a). Three levels of hazard were used; "low", "medium" and "high". A safety score and the corresponding safety index could then be generated.

The next sections present the discussion of the features of IPASS in terms of providing the potential applications as listed in Table 3.

Table 3: Potential of BIM in improving safety

\begin{tabular}{|l|c|c|c|c|c|}
\hline & \multicolumn{2}{c}{$\mathbf{N}$} & \multicolumn{2}{c}{ Mean } & \multicolumn{2}{c|}{ Std. Dev. } & Variance \\
& Statistic & Statistic & $\begin{array}{c}\text { Std. } \\
\text { Error }\end{array}$ & Statistic & Statistic \\
\hline Hazard identification (F1) & 59 & 2.66 & .140 & 1.077 & 1.159 \\
\hline Pre-project planning (F2) & 59 & 1.97 & .130 & .999 & .999 \\
\hline Clash detection (F3) & 59 & 2.29 & .130 & 1.001 & 1.002 \\
\hline Location tracking (F4) & 59 & 2.51 & .140 & 1.073 & 1.151 \\
\hline $\begin{array}{l}\text { Conformance to performance standards and } \\
\text { regulations (F5) }\end{array}$ & 59 & 2.51 & .122 & .935 & .875 \\
\hline $\begin{array}{l}\text { Safety monitoring using actual construction } \\
\text { site data (F6) }\end{array}$ & 59 & 2.64 & .134 & 1.030 & 1.061 \\
\hline Safety simulation (F7) & 59 & 2.69 & .159 & 1.221 & 1.492 \\
\hline
\end{tabular}

\section{Theoretical framework of safety aspect of IPASS}

As discussed above, DfS is a deliberate consideration at the design stage to address safety issues before construction starts on site so that hazards can be eliminated or reduced during the construction stage, resulting in fewer incidents and possible injuries. In short, DfS is designing for construction safety by implementing prevention methods in the design approach in order to achieve safe design. The theoretical basis of the Safety Aspect of the proposed IPASS was drawn from the literature review, data collected from the field study which comprised the on-line questionnaire-based survey, and an analysis of historical information from the industry and WSH Institute. Its primary objective is to assist designers in recognising hazards virtually, hence reducing risks at the source. The proposed system's algorithm is built from this theoretical framework as shown in Figure 3. The proposed theoretical framework has five features: (1) Rule Check, (2) Hazard Check, (3) Control Measure, (4) WSH Evaluation, and (5) Planning and Monitoring.

\section{Rule Check: Conformance to performance standards and regulations (F5)}

IPASS was developed with reference to Singapore's building and safety regulations (Building Control Regulations 2003; and Workplace Safety and Health (Construction) Regulations 2007) and BIM standards (Singapore BIM Guide Version 2.0 and BIM Essential Guides). Parameters 
such as depth and height of building elements in BIM models are calculated and analysed by the rule-checking system which was developed by referring to the regulations. The safety index is derived from the safety module which was built by taking into account the types of hazards and control measures outlined in the Code of Practice on Workplace Safety and Health (WSH) Risk Management (WSH Council, 2011a) and ConSASS (MOM, 2013). The property information of the basic elements that make up a building (for example, walls, columns, beams, slabs, doors, windows and so on) was defined by referring to the BIM guides of the BCA. IPASS also makes use of the international standard format called Industry Foundation Classes (IFC) to enhance collaboration, information exchange and interoperability.

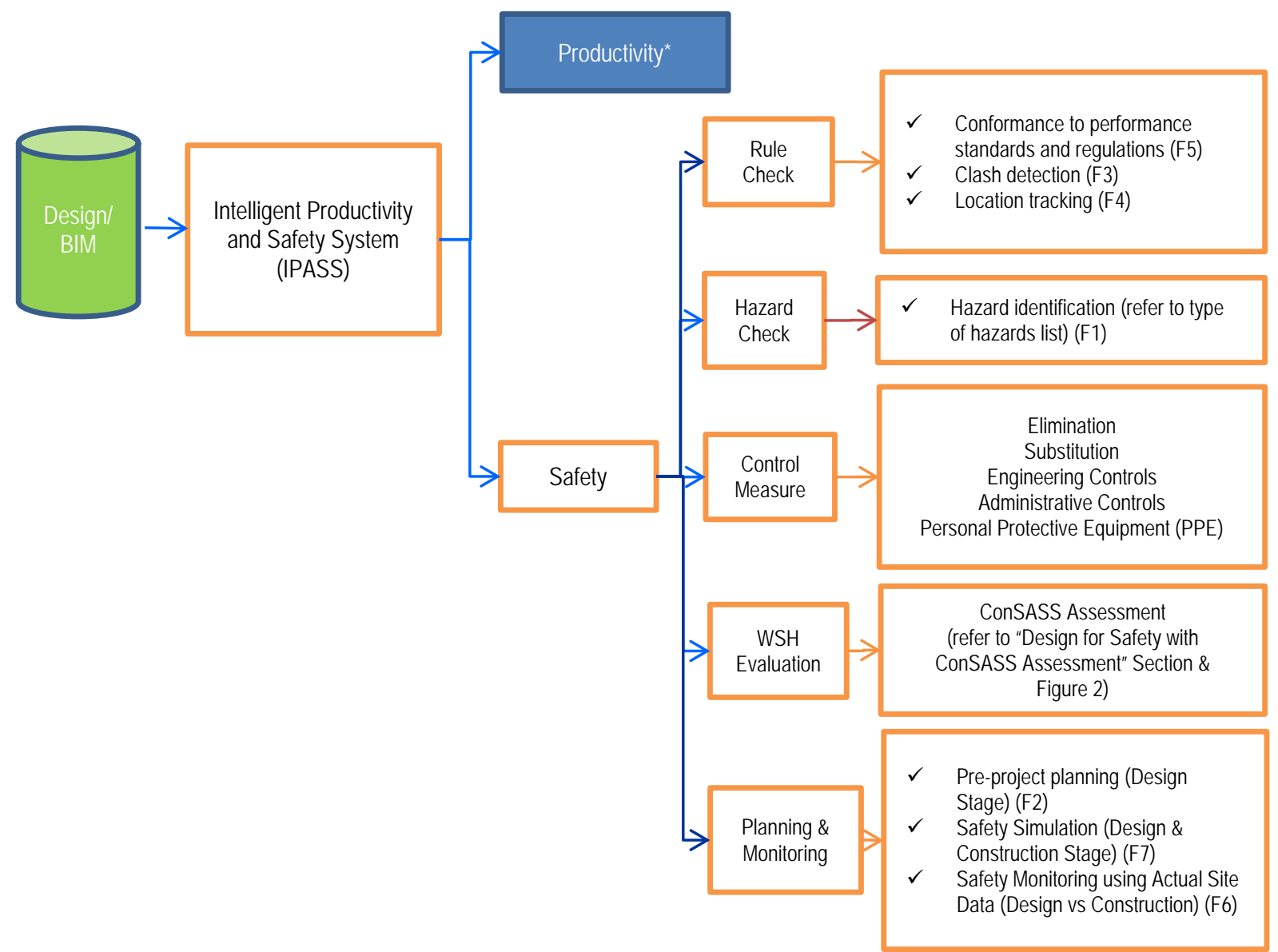

Figure 3: Proposed theoretical framework of the safety aspect of Intelligent Productivity and Safety System (IPASS)

(* The productivity aspect of IPASS is not discussed in this paper but will be elaborated on in another paper.)

\section{Rule Check: Clash detection (F3)}

The system is developed to detect clashes between different elements in the structural and wall systems. Clash detection analysis is important to allow coordination between different aspects of the building elements, as a pre-emptive measure against potential problems arising from the design. The clash detection capability of IPASS helps to identify potential conflict of elements and resolve the issue even before construction begins. The project team will be able to identify gaps and errors to rectify in the design. Moreover, clash detection helps the project team to find incompatibilities and inconsistencies much earlier, before the actual construction begins, potentially playing a crucial role in avoiding delays, saving time and resources. As such it helps to improve construction safety, and also minimizes delays due to reduced reworks during the 
construction stage. During clash detection, IPASS analyses the components in the structural and wall systems and highlights the clashes detected between the different components so that changes can be made. Simultaneous detection can also be performed by the architects and engineers; thus, BIM helps to increase the effectiveness and efficiency of the project team.

\section{Rule Check: Location tracking (F4)}

The geometric, parametric and material information of building elements in IPASS can be classified in a number of ways; for example, according to the levels of the building or the specific materials used. The classified information can be generated for the specific objects shown in the 3D model. The search function also allows the user to search for all building objects which have specific information entered into the system.

\section{Hazard Check: Hazard identification (F1), Control Measure, WSH Evaluation}

The proposed system (IPASS) has a Hazard Check feature which enables designers to identify any possible hazards in the design. The list of hazards ${ }^{1}$ was derived from historical information from the construction industry in Singapore and WSHI. No BIM-based safety system in Singapore has this list, which considers safety by cataloguing the main contributors to fatal accidents in the construction industry; this list contributes to the body of knowledge in terms of control measures. Through the development of this list it may be possible to remove the potential hazard completely, or at the very least to reduce the likelihood of the risk of exposure to that hazard. An example of a scenario in which the hazard identification and mitigation process could be utilised would be: when the system is checking for possible hazards due to "falling from height", one of the checks it conducts is to check the heights of slab openings. When the height of one slab opening is above 3 metres, the system checks for availability of anchorage points and guard rails. The system then alerts the users when these are not available. This would enable the users to take the necessary actions to avoid the possible hazard from the absence of anchorage points and guard rails.

In addition, users can also evaluate the WSH system via the ConSASS Assessment feature embedded in IPASS. This enhanced feature of the system is aimed at providing cross comparison between the design and the worksite in terms of their effectiveness in managing safety and health risks at work, enabling the project team to move away from manual ConSASS.

In developing the BIM-based system, the results (refer to Figure 2 and Table 3) of the study were critical factors which were embedded into the proposed system to calculate the safety score and safety index. From the list of hazards (refer to footnote 1) identified and the appropriate control measures taken (refer to Figure 3), the Less Hazardous Index (LHI $)^{2}$ can be generated by the proposed IPASS. On the basis of the generated LHI, the Safety Score can be computed. This safety score is computed based on the prevention and control of hazards detected in the structural and wall systems, and the ConSASS assessment. Reports on the detailed breakdown

\footnotetext{
1 (i) Fall into depth (excavation), (ii) Fall from height, (iii) Fall from MEWP, (iv) Fall from moving objects, (v) Communication, (vi) Slip and fall, (vii) Trip and fall (obstacles, poor housekeeping, uneven surfaces), (viii) Collapse of structure, support or machine (inadequate structure stage), (ix) Collapse of structure, support or machine (unsafe formwork erection stage), (x) Hit by moving objects (improper planning of layout), (xi) Hit by falling objects (no toe boards), (xii) Hit by falling objects (loose hand tools), (xiii) Crane collapse (topping/overturn), (xiv) Crane structure failure, (xv) Crane collide with building structure/other cranes, (xvi) Poor maintenance of the lifting gears, (xvii) Exposure to asbestos dust inhalation, (xviii) Exposure to particulates (inhalation), (xix) Exposure to toxic substances (inhalation), (xx) Exposure to toxic substances (skin contact), (xxi) Hot work, (xxii) Confined space (asphyxiation), (xxiii) Confined space (toxic atmoshphere), (xxiv) Confined space (oxygen enrichment), (xxv) Electrical hazard, (xxvi) Mechanical hazard, (xxvii) Noise, (xxviii) Unsafe means of access and egress between different levels in a building, and (xxix) Fire and explosion.

2 There are three types of risks; namely LOW, MEDIUM and HIGH.
} 
of the safety score are generated by the proposed IPASS, highlighting the unsafe areas of the design and inappropriate or inadequate control measures.

\section{Planning and Monitoring: Pre-project planning (F2)}

IPASS is developed with a feature which allows construction project managers to plan site activities and safety programs focusing on higher-risk trades and activities by visualising the possibility of occurrence of any of the hazards shown in footnote 1. They can also prioritise hazard mitigation strategies and intervention methods to make effective resource allocation decisions. Once the hazards have been identified, they can be avoided, or their impacts mitigated. By incorporating safety into the project at the earliest opportunity, the number of accidents and fatalities can be reduced. This focus also enables the reduction of rework through effective project planning.

\section{Planning and Monitoring: Safety simulation (F7)}

Simulation exercises that can be performed by the system include the identification of clashes and safety hazards. The results of the simulation are presented in a report to facilitate early communications of possible safety hazards and suggest preventive measures. Hence, simulation helps to identify risks factors and minimize possible delays during construction phase. The testing, analysis and simulation of the modelled building enables the project team to better understand the strengths and limitations of the design, allowing necessary improvements and amendments to be made.

\section{Planning and Monitoring: Safety monitoring using actual construction site data (F6)}

The system allows close monitoring of a building's safety performance from the earliest stage and as the construction project progresses. The system was specifically designed so that it can be used during different stages of a construction project to help designers to consider and improve the safety aspect of the design of a building. It is therefore able to perform safety monitoring using actual construction data, and incorporate various hazards as shown in Table 3. The monitoring system is a combination of visualisation of the $3 \mathrm{D}$ model generated, and studying the focus areas from different angles; such a task is impossible to perform without BIM. The project team should monitor the safety performance of a project by referring to the list of hazards, comparing the safety score obtained throughout the duration of a construction project. A further application of the system is to carry out a comparison of safety scores achieved on different projects, so that it is possible to monitor safety performance over a number of projects during a defined period.

\section{Validation}

The proposed system was validated by using the BIM model of a 10-storey building designed for an academic institution. The BIM model (Revit model) was prepared by the main contractor. The initial score (50.3) generated by the proposed IPASS was different from the actual score (manual calculation of 91.5). Steps were taken to determine why there was a difference. BIM model quality assessment was conducted to inspect the model, noting any omissions, mistakes, or areas for improvement by comparing the $2 \mathrm{D}$ drawings to the model's details. It was discovered that the BIM model did not follow a naming convention and the BIM model also had not been built with the proper levels of detail so the data could not be used in downstream applications such as analysis of safety compliance. The safety compliance could not be accurately analyzed because the building elements were modelled using generic and nonparametric objects; and each curtain wall was built by different entities, instead of one entity. Once the BIM model had been built with a proper naming convention and to the proper levels 
of detail to make it compliant with the provisions of the Singapore BIM modelling guides, the two scores generated were quite similar (90.7 [IPASS] vs 91.5 [manual]).

In addition to the BIM model of the 10-storey building, the proposed IPASS was also validated by using the BIM models of another eight virtual projects. These eight BIM models (ArchiCAD models) were built by 80 Fourth Year undergraduate students (ten students per project) under a module which forms part of the B.Sc. Project and Facilities Management program at the National University of Singapore. ${ }^{3}$ The steps described above were repeated for each of these eight BIM models. The scores generated by IPASS were very similar to the manually calculated scores of these eight BIM models, again, after the BIM models had been built with proper naming convention and levels of detail such that they complied with the BIM modelling guides.

The validation exercise provided useful lessons on the features, input requirements and capabilities of IPASS. The validation process identified limitations for implementation of IPASS, due to incorrect scores being generated, with two potential causes found for these discrepancies. First, there were technical errors due to the loss of IFC data during the import-export process. In this case, it was found that it is important to ensure the properties of the materials have been correctly input into the corresponding BIM authoring tools before exporting the model into the IFC format. Second, human error can result in naming errors or input errors so that the BIM model does not fit the provisions of the modelling guide. For this reason, BIM quality assurance is necessary in order to make sure the BIM model is configured to enable any applications to proceed properly.

This validation exercise highlighted the importance of the quality of the BIM models; it was evident that the safety scores generated by IPASS can only be done after a BIM Model Quality Assessment has been carried out to check the modelling techniques, content, completeness, and naming convention. From the validation with nine BIM models of different authoring tools, it can be seen that the safety scores generated by IPASS were very similar to those of the manual calculations. The validation results showed that IPASS is able to generate safety scores for any project as long as the BIM models are built with proper naming convention, and proper levels of detail, in accordance with BIM modelling guides.

\section{Conclusion}

The aim of this paper is to discuss the theoretical framework of the Safety Aspect of a BIM System for determining the safety index in the proposed IPASS. IPASS is proactive, and will fulfil a need in the construction industry in Singapore. The safety aspect of the system is based on the premise that safety should be considered at the design stage, with BIM as a tool to facilitate it. The system incorporates the principles of DfS by identifying risks and incorporating safety at the earliest stage of design. ConSASS assessment is also included to evaluate the capabilities of each contractor in managing WSH risks.

IPASS comes with the Hazard Check feature which enables the designers to identify hazards of their design at the earliest opportunity. Thus, the number of accidents and fatalities can be reduced. The focus is also on reducing rework through effective project planning. For the purpose of this study, a preliminary safety hazard library was developed based on the main contributors to fatal accidents in the construction industry. The Control Measures feature is also one of the primary features that allow the project team to consider the precautions at the design stage with appropriate actions that can be taken to reduce the potential of the hazard or to reduce the level of its risk by adding precautions/control measures, as necessary. Besides the

\footnotetext{
${ }^{3}$ PF4206 Building Information Modelling is an elective module taken mainly by Final Year students. It is assessed on a series of tasks including a major group project which involved the creation of a BIM in response to a set of project parameters. The models are assessed by a panel of judges drawn from local and overseas BIM experts.
} 
Control Measures feature, another contributor to knowledge is the creation of the Less Hazardous Index (LHI). From the list of hazards identified and the appropriate control measures to be taken, the LHI can be generated by IPASS. From the generated LHI, the Safety Score can be computed. Reports on the detailed breakdown of the safety score are generated by IPASS, highlighting the unsafe areas of the design and the inappropriate control measures.

The possible limitations of this study are now considered. It should be stated that it might not be appropriate to draw conclusions concerning DfS, and using BIM for enhancing safety performance throughout the construction industry, given the relatively small number of respondents, and the size of the response rate (59 responding companies, indicating a response rate of $7.54 \%$ ). According to the relevant authority there is a very low percentage of companies using BIM for multi-discipline activities, even fewer would therefore be using BIM for enhancing safety (BCA, 2015), which had a negative impact on response rates. Moreover, according to Cheah et al. (2004) as long as the intent of the study was neither to precisely identify a "formula" for success, nor to draw statistical inferences, it would not require a larger sample size. This research does not attempt to reconcile the many differences between individual firms and construction industry conditions; rather, it is meant to extract critical factors that contribute to the success of using BIM for enhancing safety at the project level. The data collected for this study adequately supported the application of the method that was designed to form the basis for the development of a new BIM system for enhancing safety. Thus, the data were judged sufficient for the purposes of this research despite the limitations which have been mentioned here.

The practical implications of IPASS are: (a) it enables collaboration among project stakeholders as they can base their work on an analysis of the safety performance before the project starts, and as it progresses, also; (b) it is suggested that the BIM model submitted to the authorities for building plan approval should be the one which is used for the IPASS application. The originality/value of IPASS is that it has rule-checking, hazard identification and quality checking capabilities. Thus, it is able to identify hazards and risks with these capabilities. IPASS enables practitioners to check mistakes and the rationality of a design. It also helps to mitigate risks as there are built-in safety measures/controls rules to overcome the problems caused by design deficiency, wrong-material-choice, and so on.

\section{Acknowledgements}

The authors gratefully acknowledge the funding received from the Workplace Safety and Health Institute (WSH Institute) of the Ministry of Manpower (MOM). They are also grateful to the collaborating organisations, the Building and Construction Authority (BCA) and Samwoh Corporation Pte Ltd. They would also like to thank the practitioners who responded to the questionnaire survey.

\section{References}

Azhar S. and Behringer A. (2013) A BIM-based Approach for Communicating and Implementing a Construction Site Safety Plan. Proc., $49^{\text {th }}$ ASC Annual International Conference Proceedings, San Luis Obispo.

Behm, M. (2005a) Design for construction safety: an introduction, implementation techniques, and research summary. In: ASSE (American Society of Safety Engineers), ASSE Professional Development Conference and Exposition. New Orleans, USA, 12-15 June 2005. New Orleans: ASSE.

Behm, M. (2005b) Linking construction fatalities to the design for construction safety concept. Safety Science, 43, p.589-611. doi: https://doi.org/10.1016/j.ssci.2005.04.002

Benjaoran, .V. and Bhokha, S. (2010) An integrated safety management with construction management using 4D CAD model. Safety Science, 48(3), p.395-403. doi: https://doi.org/10.1016/j.ssci.2009.09.009 
Building and Construction Authority, (2011) Media Release: Construction Productivity Roadmap to chart transformation of the construction sector. BCA. Available at: <http://www.bca.gov.sg/newsroom/others/pr03032011_CPA.pdf>. [Accessed 20 February 2016].

Building and Construction Authority, (2013) Building Information Modelling. [online] Available at: <https://www.bca.gov.sg/bim/bimlinks.html> [Accessed 23 February 2016].

Building and Construction Authority, (2014a) BCA Directory of Registered Contractors and Licensed Builders. [online] Available at: $<$ http://www.bcadirectory.sg/> [Accessed 23 February 2016].

Building and Construction Authority, (2014b) Code of Practice on Buildability, 2014 Edition. [pdf] BCA. Available at: < http://www.bca.gov.sg/BuildableDesign/others/copbdnov2014.pdf> [Accessed 20 February 2016].

Building and Construction Authority, (2015) Construction Productivity and Capability Fund. [online] Available at: <http://www.bca.gov.sg/CPCF/cpcf.html $>$ [Accessed 23 February 2016].

Cheah C. Y. J., Garvin M. J. and Miller J. B. (2004) Empirical study of strategic performance of global construction firms. Journal of Construction Engineering and Management, 130(6), p.808-817. doi: https://doi.org/10.1061/(ASCE)0733-9364(2004)130:6(808)

Choi, J., Choi, J. and Kim, I. (2014) Development of BIM-based evacuation regulation checking system for high-rise and complex buildings. Automation in Construction, 46, p.38-49. doi: https://doi.org/10.1016/j.autcon.2013.12.005

Gambatese, J. A., Hinze, J. and Haas, C. T., 1997. Tool to design for construction worker safety. Journal of Architectural Engineering, 3(1), p.32-41. doi: https://doi.org/10.1061/(ASCE)1076-0431(1997)3:1(32)

Gambatese, J., Behm, M. and Rajendran, S. (2008) Design's role in construction accident causality and prevention: Perspectives from an expert panel. Safety Science, 46, p.675-691. doi: https://doi.org/10.1016/j.ssci.2007.06.010

Gangolells, M., Casals, M., Forcada, N., Roca, X. and Fuertes, A. (2010) Mitigating construction safety risks using prevention through design. Journal of Safety Research, 41, p.107-122. doi: https://doi.org/10.1016/j.jsr.2009.10.007

Gu, N. and London, K. (2010) Understanding and facilitating BIM adoption in the AEC industry. Automation in Construction, 19(8), p.988-999. doi: https://doi.org/10.1016/j.autcon.2010.09.002

Hadikusumo B.H.W. and Rowlinson S. (2002) Integration of virtually real construction model and design-for-safety process database, Automation in Construction, 11(5), p.501-509. doi: https://doi.org/10.1016/S0926$\underline{5805(01) 00061-9}$

Hammad A., Setayeshgar S., Zhang C. and Asen Y. (2012) Automatic Generation of Dynamic Virtual Fences As Part of BIM-Based Prevention Program for Construction Safety, Proc., Proceedings of the 2012 Winter Simulation Conference (WSC), Berlin, Germany 2012. doi: https://doi.org/10.1109/WSC.2012.6465164

Hecker, S. and Gambatese, J. A. (2003) Safety in Design: A Proactive Approach to Construction Worker Safety and Health. Applied Occupational and Environmental Hygiene, 18(5), p.339-342. doi: https://doi.org/10.1080/10473220301369

Hinze, J. and Wiegand, F. (1992) Role of Designers in Construction Worker Safety. Journal of Construction Engineering and Management, 118(4), p.677-684. doi: https://doi.org/10.1061/(ASCE)0733-9364(1992)118:4(677)

Joint MND-MOM Review Committee, (2005) Report of the Joint MND-MOM Review Committee on Construction Safety. Singapore: JRC.

Ku, K., 2014. Design Risk Management Practices and Assessment Tools for Safety in Construction: Opportunities for BIM. In: Aulin, R. and Ek, A. (Eds.), Proceedings of CIB W099 Achieving Sustainable Construction Health and Safety. Lund, Sweden, 2-3 June 2014. CIB W099.

Malekitabar, H., Ardeshir, A., Sebt, M.H., Stuoffs, R. (2016) Construction safety risk drivers: A BIM approach. Safety Science 82, p.445-455. doi: https://doi.org/10.1016/j.ssci.2015.11.002

Melzner J., Hollermann S., Korchner S. and Bargstadt H.J. (2013) Model-based Construction Work Analysis Considering Process-related Hazards, Proc., Proceedings of the 2013 Winter Simulation Conference, IEEE, Washington, D.C., 2013, p.3203-3214. doi: https://doi.org/10.1109/wsc.2013.6721686

Ministry of Manpower, (2013) A Guide to the Construction Safety Audit Scoring System (ConSASS). [pdf] MOM. Available at: $<$ http://www.mom.gov.sg/ / media/mom/documents/services-forms/safetyhealth $/ \mathrm{a} \% 20$ guide $\% 20$ to $\% 20$ the $\% 20$ consass.pdf $>$ [Accessed 22 February 2016].

Ministry of Manpower, (2015) Requirements for a Safety and Health Management Systems. [online] Available at:

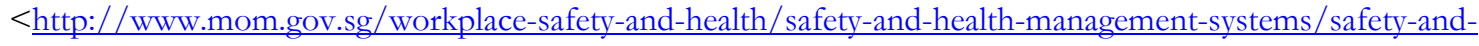
health-management-system-requirements $>$ [Accessed 23 February 2016].

Rozenfeld O., Sacks R. and Rosenfeld Y. (2009) "CHASTE": construction hazard assessment with spatial and temporal exposure, Construction Management and Economic 27(7), p.625-638. doi: https://doi.org/10.1080/01446190903002771

Safe Work Australia, (2012) Safe Design of Structures: Code of Practice. Canberra: Safe Work Australia. 
Schulte, P. A., Rinehart, R., Okun, A., Geraci, C. L. and Heidel, D. S. (2008) National Prevention through Design (PtD) Initiative. Journal of Safety Research, 39(2), p.115-121. doi: https://doi.org/10.1016/j.jsr.2008.02.021

Slaughter E.S. (2003) The link between design and process: dynamic process simulation models of construction activities, 4D CAD and Visualization in Construction: Developments and Applications, Swets \& Zeitlinger, Gainesville, FL, p.145-164. doi: https://doi.org/10.1201/9780203971123.ch7

Smith, D. (2007) An introduction to Building Information Modelling (BIM). Journal of Building Information Modelling, Fall, p.12-14.

Sulankivi K., Makela T. and Kiviniemi M. (2009) BIM-based site layout and safety planning. Proc., $1^{\text {st }}$ International Conference on Improving Construction and Use through Integrated Design Solutions, CIB IDS, Finland, 2009.

Sulankivi K., Zhang S., Teizer J. Eastman C.M., Kiviniemi M., Romo I. and Granholm L. (2013) Utilization of BIMbased Automated Safety Checking in Construction Planning, Proc., CIB World Building Conference, Brisbane, Australia.

Teo E. A. L., Ofori G. and Tjandra I. K. (2015) Building Information Modelling (BIM) for Safety Improvement in Singapore Construction. Proceedings of the 2015 CIB W099 Conference: Benefitting Workers and Society through Inherenetly Safe(r) Construction, Belfast, 9-11 September 2015.

Toole, T. M. and Gambatese, J. (2008) The Trajectories of Prevention through Design in Construction. Journal of Safety Research, 39, p.225-230. doi: https://doi.org/10.1016/j.jsr.2008.02.026

Wetzel E. M. and Thabet W. Y. (2015) The use of a BIM-based framework to support safe facility management processes, Automation in Construction, 60, p.12-24. doi: https://doi.org/10.1016/j.autcon.2015.09.004

Winfield, M. (2015) How BIM can assist the implementation of the CDM Regulations 2015. [online] Available at:

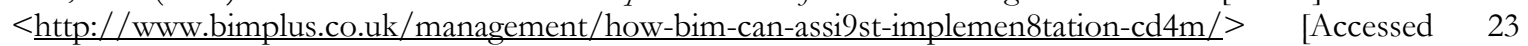
February 2016].

Workplace Safety and Health Act 2009. (c.354a) Singapore: MOM.

Workplace Safety and Health Council, (2007) Implementing WSH 2015 for Construction Industry. Singapore: WSH Council.

Workplace Safety and Health Council, (2008) Case Studies: Construction Industry. [pdf] WSH Council. Available at: $<$ https://www.wshc.sg/files/wshc/upload/cms/file/Falls\%20From\%20Height.pdf $>$ [Accessed 23 February 2016].

Workplace Safety and Health Council, (2010) Implementing WSH 2018 for the Construction Sector in Singapore: Towards a Progressive and Pervasive Safety and Health Culture [pdf] WSH Council. Available at: $<$ https://www.wshc.sg/files/wshc/upload/cms/file/WSH $\% 20$ Construction $\% 20$ Sectoral $\% 20$ final lowres.pdf $>$ [Accessed 23 February 2016].

Workplace Safety and Health Council, (2011a) Code of Practice on Workplace Safety and Health (WSH) Risk Management. [pdf] WSH Council. Available at: < https://www.wshc.sg/files/wshc/upload/cms/file/2014/RMCP 2012.pdf> [Accessed 22 February 2016].

Workplace Safety and Health Council, (2011b) Guidelines on Design for Safety in Buildings and Structures. [pdf] WSH Council. <https://www.wshc.sg/files/wshc/upload/cms/file/2014/DfS Guidelines Revised July2011.pdf > [Accessed 23 February 2016].

Workplace Safety and Health Council, (2015) Construction Industry WSH Action Plans 2015. [pdf] WSH Council. Available

at:<https://www.wshc.sg/files/wshc/upload/event/file/Construction_Industry_WSH_Action_Plans_2015(2). pdf $>$ [Accessed 22 February 2016].

Workplace Safety and Health Council and Ministry of Manpower, (2013) Curriculum Development Advisory: Construction Safety Orientation Course for Workers (CSOC). [pdf] WSH Council and MOM. Available at: $<$ https://www.wshc.sg/files/wshc/upload/cms/file/2014/CSOC.pdf > [Accessed 23 February 2016].

Workplace Safety and Health Institute, (2015a) Workplace Safety and Health Report, 2014 National Statistics. [pdf] WSH Institute. Available at: $\quad<\quad$ https://www.wshinstitute.sg/files/wshi/upload/cms/file/WSHI $\% 20$ National $\% 20$ Statistics $\% 20$ Report $\% 202014 . p d f>$ [Accessed 23 February 2016].

Workplace Safety and Health Institute, (2015b) Workplace Safety and Health Report, January-June 2015 National Statistics. [pdf] WSH Institute. Available at: <http://www.lsh.sg/wp-content/uploads/2015/09/WSH-InstituteNational-WSH-Statistics-Report-Jan-Jun-2015.pdf $>$ [Accessed 23 February 2016].

Yong, G. K., (2008) Speech at WSH Council 2008 Construction CEO Summit. [online] Available at: $<$ http://www.mom.gov.sg/newsroom/speeches/2008/speech-by-mr-gan-kim-yong-acting-minister-formanpower-at-the-wsh-council-2008-construction-ceo-summit-18-november-2008-regent-hotel> [Accessed 23 February 2016].

Zhang S., Boulcamp F. and Teizer J. (2014) Ontology-based semantic modelling of safety management knowledge, 2014 International Conference on Computing in Civil and Building Engineering, American Society of Civil Engineers, Orlando, FL, p.2254-2262. 
Zhang S., Boulcamp F. and Teizer J. (2015a) Ontology-based semantic modelling of construction safety knowledge: towards automated safety planning for job hazard analysis (JHA), Automation in Construction, Elsevier 52, p.29-41. doi: https://doi.org/10.1016/j.autcon.2015.02.005

Zhang S., Sulankivi K., Kiviniemi, M., Romo, I., Eastman, C.M., Teizer, J. (2015b) BIM-based fall hazard identification and prevention in construction planning, safety science, Safety Science, Elsevier 72, p.31-45. doi: https://doi.org/10.1016/j.ssci.2014.08.001

Zhang S., Teizer, J., Lee, J., Eastman, C. and Venugopal, M. (2013) Building Information Modeling (BIM) and Safety: Automatic Safety Checking of Construction Models and Schedules. Automation in Construction, 29, p.183195. doi: https://doi.org/10.1016/j.autcon.2012.05.006

Zhang S., Teizer, J., Pradhananga N. and Eastman C. M. (2015) Workforce location tracking to model, visualize and analyse workspace requirements in building information models for construction safety planning, Automation in Construction, 60, p.74-86. doi: https://doi.org/10.1016/j.autcon.2015.09.009

Zhou W., Whyte J., Sacks R. (2012) Construction safety and digital design: a review. Automation in Construction, 22, p.102-111. doi: https://doi.org/10.1016/j.autcon.2011.07.005

Zou, P. X. W. and Sunindijo, R. Y. (2015) Strategic Safety Management in Construction and Engineering. Hoboken: John Wiley and Sons. doi: https://doi.org/10.1002/9781118839362

Zou, Y., Kiviniemi, A. and Jones, S.W. (2016) "A review of risk management through BIM and BIM-related technologies”, Safety Science, 2016,1. doi: https://doi.org/10.1016/j.ssci.2015.12.027 